Thomas W. L. Scheeren

\section{Monitoring the microcirculation in the critically ill patient: reflectance spectroscopy}

Accepted: 30 December 2010

Published online: 11 March 2011

(C) The Author(s) 2011. This article is published with open access at Springerlink.com

An author's reply to this comment is available at:

doi:10.1007/s00134-011-2203-7.

Electronic supplementary material

The online version of this article (doi:10.1007/s00134-011-2197-1) contains supplementary material, which is available to authorized users.

Dear Editor,

I read with great interest and pleasure the excellent overview of the most common methods currently used to monitor the microcirculation by De Backer and colleagues [1]. The expertise of this group of authors with most of the methods described in their review of innumerable original publications was clearly evident. However, the section on reflectance spectroscopy is rather short, suggesting that they may lack in-depth practical experience with that specific method. In particular, the last sentence on recent developments in the technique is incorrect and needs to be explained more specifically.

The first device using reflectance spectroscopy (EMPHO) was limited to perpendicular probes for mucosa measurements and was based on spectrophotometry only. Nevertheless, it has been used in numerous experimental and clinical studies performed by our group for assessing the effects of various factors and agents, such as positive airway pressure, intraabdominal pressure, hypercapnia, cardiopulmonary bypass, vasoactive drugs and anaesthetics, on the splanchnic microcirculation [for references, see the Electronic Supplementary Material (ESM)].

The latest development using reflectance spectroscopy is incorporated in the $\mathrm{O} 2 \mathrm{C}$ (oxygen to see) device (Lea, Giessen, Germany). The technology of the $\mathrm{O} 2 \mathrm{C}$ device is based on two physical principles: reflection spectroscopy and the laser Doppler technique. Compared to the EMPHO device, the $\mathrm{O} 2 \mathrm{C}$ instrument integrates both techniques in a much smaller device because the rotating filter wheel has been replaced by a CCD-spectrometer and the xenon high-pressure lamp by a small light source optimised for fibre optics.

Specific probes are used to introduce white light (wavelengths 500-800 nm) and laser light (wavelength $830 \mathrm{~nm}$ ) simultaneously into the tissue. A part of the light spectrum is absorbed when the white light interacts with the erythrocytes, and this absorbed portion assumes the colour of the haemoglobin as a measure of its oxygen saturation. The laser light experiences a frequency displacement due to the moving erythrocytes (the so-called Doppler Shift), and this displacement is a measure of their velocity. The sum of all erythrocytes and their velocity is a measure of blood flow (volume flow) in the complex network of capillaries.

With this device the following parameters can be measured simultaneously in tissue:

- the oxygen saturation of haemoglobin $\left(\mu \mathrm{HbO}_{2}\right)$ at the venous end of the capillaries (the so-called "last meadow");

- the regional amount of haemoglobin $(\mathrm{rHb})$ in the micro-blood vessels as a measure of its blood volume and for capillary density;
- the velocity of the blood in microcirculation;

- the flow of blood in the microcirculation.

The main advantage of this technology when assessing microvascular blood flow is that this combination of parameters allows the determination of regional oxygen consumption $\left(\mathrm{rVO}_{2}\right)$ in the tissue as a direct measure of tissue viability. The metabolism may be a more important parameter than the heterogeneity of perfusion, which is considered to be a key to monitor sepsis (for details, see ESM).

The method has been used clinically to assess the microvascular response in patients with septic shock [2], to monitor the effects of extreme anaemia [3] or flap viability [4] and to predict wound healing in burn injury [5].

In conclusion, the combination of reflection spectroscopy and laser Doppler (O2C) may offer a useful enlargement of the diagnostic tools available to the clinician for assessing microvascular blood flow and tissue oxygen consumption.

Open Access This article is distributed under the terms of the Creative Commons Attribution Noncommercial License which permits any noncommercial use, distribution, and reproduction in any medium, provided the original author(s) and source are credited.

\section{References}

1. De Backer D, Ospina-Tascon G, Salgado D, Favory R, Creteur J, Vincent JL (2010) Monitoring the microcirculation in the critically ill patient: current methods and future approaches. Intensive Care Med 36:1813-1825. doi 10.1007/s00134-010-2005-3

2. Sakr Y, Gath V, Oishi J, Klinzing S, Simon TP, Reinhart K, Marx G (2010) Characterization of buccal microvascular response in patients with septic shock. Eur J Anaesthesiol 27:388-394 
3. Menzebach A, Mutz C, Scheeren TW (2008) Microcirculatory monitoring of a Jehovah's Witness suffering from haemorrhagic shock. Eur J Anaesthesiol 25:81-83

4. Hölzle F, Rau A, Löffelbein DJ, Mücke T, Kesting MR, Wolff KD (2010)

Results of monitoring fasciocutaneous, myocutaneous, osteocutaneous and perforator flaps: 4-year experience with 166 cases. Int J Oral Maxillofac Surg 39:21-28
5. Merz KM, Pfau M, Blumenstock G, Tenenhaus M, Schaller HE, Rennekampff HO (2010) Cutaneous microcirculatory assessment of the burn wound is associated with depth of injury and predicts healing time. Burns 36:477-482
T. W. L. Scheeren $(\varangle)$

Department of Anaesthesiology,

University Medical Center Groningen,

University of Groningen,

Groningen, The Netherlands

e-mail: t.w.l.scheeren@anest.umcg.nl

Tel.: +31-50-3616161

Fax: $+31-50-3613763$ 